\title{
Cameroonian ESL Teachers' Linguistic Perceptions and Some Phonological Aspects of Their English
}

\author{
Julius M. Angwah \\ University of Yaounde I
}

\begin{abstract}
Despite the popular credence that the nature of English in Cameroon shifts significantly from Standard British English, ESL teachers seem to think differently about their competencies in the English language. Consequently, I set out to investigate the correlation between ESL teachers' linguistic perceptions and some phonological aspects of their speech. Three theoretical paradigms guided this study - Labov's (1966) correlation model, Kachru's (1985) World Englishes Paradigm and Corder's (1967) Error Analysis. A total of 75 ESL teachers in the country, constituted the sampled population of the study. A questionnaire, with close and open-ended questions, was constructed to gain an understanding of their linguistic perceptions. A test of 10 sentences, with targeted phonological variables $\left(\mathrm{d} 3, \mathrm{t} \int, \partial, \theta, \partial, 3\right.$, ,, , әひə, and avə), was conceived and the informants were asked to read them aloud while the investigators tap-recorded their phonological renditions. The data was then transcribed and compared to their linguistic perceptual claims. Essentially, the results revealed a significant gap between the respondents' linguistic perceptions and their phonological renditions
\end{abstract}

Keywords: Cameroonian, Linguistic perception, Phonological aspects, English

DOI: $10.7176 /$ JLLL/57-02

Publication date:June $30^{\text {th }} 2019$

\subsection{Introduction}

There have been considerable arguments (see, for example, Masanga 1983; Mbangwana 1987; SimoBobda 1994; Anchimbe 2006, Ngefac 2008, 2010 and Atechi 2010) to justify the fact that the English language in postcolonial multilingual Cameroon differs significantly from Standard British English (SBE henceforth) at all linguistic levels. Even at that, users of English in the country, for the most part, often think highly of their English. It is not uncommon to observe educated Cameroonians overtly appreciate the variety of English they speak - arguing emphatically that, though Cameroon English (CamE henceforth) is a reality in the country, they are speakers (users) of SBE or Standard American English (SAE hereafter) as the case maybe. The feeling is such that accepting that one speaks Cameroon English is almost as good as accepting that one is uneducated. This feeling seems to have characterised the mentality of ESL teachers whom after taking a few English language courses in the university, tend to feel as though the mastery of SBE phonology is as easy as passing a course on English phonology. Observably, the effects are often dramatic - they sometimes strive to import features of American English speech or use hyper expressions to justify their claims. This attitude of adhering to the almost unattainable Western standards, instead of going along with the realistic context-specific standards, projects them as victims of what Bokamba (2007) refers to as "ukolonia". As a result of this unprecedented phenomenon, there is the dire need to find out the extent to which ESL teachers' perception of their English correlates with their phonological renditions in a bid to further underscore the dire need for policy makers to precipitate the identification, codification and standardization process of CamE.

\subsection{Literature Review}

In this study, we use perception synonymously with attitude. Linguistic perception in this respect has, by large, received substantial attention across the globe, in the past three or four decades. One of the authorities in this domain is arguably Labov (1966). He reports that some of his informants who identified themselves with mainstream AmE actually produced non-features of mainstream AmE. His most outstanding finding was the rendition of the post-vocalic $/ \mathrm{r} /$ in such words as "car" and "floor". He realized that the post-vocalic pronunciation of $/ \mathrm{r} /$ was more frequent in the speech of the upper working class than in the speech of the middle class, and that the upper working class, in an effort to sound like the middle class, ended up realizing $/ \mathrm{r} /$ in almost every position; thus, confirming their statuses as victims of the hypercorrection syndrome. This inconsistency is also evident among Japanese learners of English. Strange (1982) reports that the perceptual mastery of $/ \mathrm{r} /$ and $/ 1 /$ among Japanese learners of English does not necessarily reflect actual use and may even lag behind in acceptable production. These findings reflect the situation of TESOL in Korea. Borden et al, (1983) report that, though Korean learners of English believe in their appropriate use of $/ \mathrm{r} /$ and $/ 1 /$, they use these sounds interchangeably. They observe that Korean learners of English have more native-like phonemic identification and self-perception than production, and suggest that perceptual abilities might be a prerequisite for accurate production. It is, therefore, not surprising when Neufeld (1988) concludes that his learners often perceptually detect sounds better than they produce them. While scholars are of the opinion that learners, who demonstrate 
well-established perceptual categories, are likely to manifest accurate production (Barry 1989 and Grasseger 1991), the extent to which this could be true of ESL teachers, in Cameroon, is our major preoccupation in this investigation.

Observably, it would seem the situation in Cameroon is even more uncertain with numerous varieties of English, including CamE, Cameroon Francophone English (CamFE), American English (AmE), British English (BrE), and Nigerian English (NigE), co-existing in the country (Mbangwana 1987, Simo Bobda 1994, Anchimbe 2004, Ngefac 2008, Atechi and Angwah 2016). The coexistence of these numerous varieties, in the country, has brought about serious controversies with regard to who speaks what and how well. Atechi $(2006: 28)$ contends that the multilingual status of postcolonial Cameroon gives room to certain attitudinal tendencies that shape peoples' ideologies, identities, cultures, and perceptions. Consequently, people resort to defining their identities, based on languages or varieties of languages. Interestingly, the multilingual status of Cameroon has induced various attitude or perception towards the varieties of English in the country. Mbangwana (1987:423) observes that the Cameroonian public fully accepts CamE and stigmatizes efforts to speak English with native accent. This finding is equally true of such ESL contexts as Ghana (Sey 1973:1), Nigeria (Bamgbose1998), and some parts of East Africa (Schmied 2006:191). Later studies, in Cameroon, have reported a gradual growth of CamE fans. Though Achimnbe (2004) reports that just 4\% of his informants had a positive attitude towards CamE, this statistics was, however, modified in 2008 when Aloysius Ngefac realized that up to $32 \%$ of his informants preferred CamE. Most recently, Atechi and Angwah (2016) have reported that $84.58 \%$ educated Anglophone Cameroonians would prefer CamE as the model in the English Language teaching industry, considering the arguably impracticability of SBE or SAE in the country. From these reports, one can deduce two very important elements which are relevant to the current study. First, it demonstrates a steady growth of interest towards CamE. Second, it paints a dense multi linguistic diversity which is likely to lead to deviations in the variety of English spoken in the country. However, contrary to these studies, this paper, from an attitudinal perspective, investigates the co-relation between ESL teachers' linguistic perceptions and some phonological aspects of their English in a bid to further raise awareness on the state of English language use in the English Language Teaching and learning industry in Cameroon in a bid to add a voice to the current call for the identification, codification and standardization process of CamE.

\subsection{Research Questions}

This study was, therefore, guided by the following research questions:

1. How do ESL teachers perceive their English?

2. What are some of the phonological aspects of ESL teachers' English?

3. What is the correlation between ESL teachers' linguistic perceptions and their phonological renditions?

4. What are the implications of the findings to the nature of English language teaching and learning in Cameroon and the standardization process of Cameroon English?

\subsection{Methodology}

75 trained ESL teachers were identified as informants for the study. All the informants had had a minimum of one year experience in the teaching of English as a second language. A questionnaire and a short oral test constituted the main instruments of data collection. The questionnaire was made up of 10 questions -8 closeended and 2 open-ended questions. While the principal question was meant to find out the variety of English the informants claim to speak, the other questions were meant to ascertain their consistencies to their claims. An oral proficiency test, which was made up of 10 short sentences, with targeted phonological variables $\left(\mathrm{d} 3, \mathrm{t} \int, \mathrm{\partial}, \theta, \int, \partial\right.$, 3, əu, әઇə, and avə), was administered to all the informants. The informants were simply required to feel in the questionnaire and read out the 10 sentences, while a tape recorder was used to record their speeches.

\subsection{Results}

\subsubsection{Teachers' Linguistic Perception}

It would seem the prestige that is accorded to SBE, in Cameroon, has a significant influence on ESL teachers' perceptions of the variety of English they speak and use in their classrooms. This is so because a significant number of them identified more with SBE than with the other varieties and though some identified with CamE, the percentage was not quite significant as could be seen on the following table.

\begin{tabular}{lll}
\hline Linguistic preferences & Freq & $\%$ \\
\hline CamE & 10 & $13.34 \%$ \\
SBE & 64 & $85.33 \%$ \\
SAE & 1 & $1.33 \%$ \\
NigE & 0 & $0 \%$ \\
Total & 75 & $100 \%$ \\
\hline
\end{tabular}

Table 1: Informants' Perception of their English 
The informants were seemingly quite consistent with their claims of SBE usage in the classroom, but they also indicated their extensive preference of CamE especially in informal contexts. Consider, for instance, the following table which presents the informants' distribution of SBE, CamE and SAE in terms of contexts of use.

\begin{tabular}{lllll}
\hline Contexts & SBE Usage/ Frq (\%) & CamE Usage/ Frq (\%) & SAE Usage/ Frq (\%) & Total Frq (\%) \\
\hline Classroom & $68(90.67 \%)$ & $06(08 \%)$ & $01(1.33 \%)$ & $75(100 \%)$ \\
Colleagues & $03(4 \%)$ & $72(96 \%)$ & $00(00 \%)$ & $75(100 \%)$ \\
Home & $00(00 \%)$ & $75(100 \%)$ & $00(00 \%)$ & $75(100 \%)$ \\
\hline
\end{tabular}

\section{Table 2: Informants' Distribution of SBE, CamE and SAE According to Contexts.}

From these contextual preferences, most ESL teachers in the country seem to share the opinion that CamE is a disreputable variety which is only good enough for phatic communion and hardly for such formal contexts as the classroom and this is why they distance themselves from it and identify more with the "reputable" SBE variety. We, however, noticed that those who sympathized with CamE had either done the Masters Degree program or were in the program or were simply informed by their long experiences in the teaching of English as a second language. While the English Language Departments in the teacher training colleges offer courses on Sociolinguistics, the New Englishes or World Englishes, in practical terms, ESL teachers' linguistic perceptions seem to be guided either by the ministerial stance on SBE as the model in the English Language teaching and learning industry or by fears of being marked as incompetent. Sadly, their perceptions do not seem to corroborate with their performances in real life language use.

\subsubsection{The Phonological Aspects of ESL Teachers' Speech}

While there are visible disparities between Inner Cycle and Outer Cycle Englishes, at all linguistic levels, there is an academic conclusion that such differences are markedly prominent at the level of phonology (Wolf, HansGeorg 1963). Consequently, a phonological description of ESL teachers' language can better project the variety

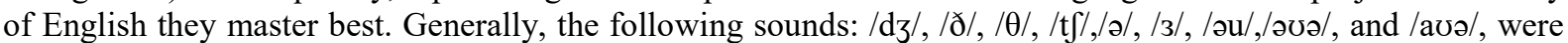
purposefully inserted in the following words: "Cabbage" "church", "village", "southern", "the", "about", "power", "thought", "goat" and "slower" which were also further inserted in real life sentences. The table below presents the sounds, the words and the sentences in which they were tested.

\begin{tabular}{|c|c|c|c|}
\hline Sounds & Words & RP Transcription & Sentences \\
\hline$/ \mathbf{d} 3 /$ & Cabbage & Kæbidz & John sent the cabbage from southern country to the village. \\
\hline /ð/ & Southern & 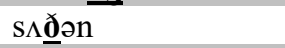 & John sent the cabbage from southern country to the village. \\
\hline$/ \theta /$ & Thought & $/ \theta \overline{\mathrm{pt}} /$ & I thought Paul was a good student. \\
\hline$/ \mathbf{t} \mathbf{j} /$ & Church & $/ \mathbf{t} \int 3 \mathbf{t} \mathbf{j} /$ & Lawyers don't go to church. \\
\hline$/ a /$ & $\underline{\text { About }}$ & /obaut/ & Paul spoke for about an hour. \\
\hline$/ 3 /$ & Church & $\mathrm{t} \int_{\underline{\underline{3}}}^{\mathrm{t}} \int$ & Lawyers don't go to church. \\
\hline /əu/ & Goat & /gəot/ & James is inside, searching for the goats. \\
\hline /әбә/ & Slower & /sloü/ & Mother's car is slower than father's. \\
\hline /avə/ & Hour & /avo/ & Paul spoke for about an hour. \\
\hline
\end{tabular}

Table: 3 SBE Segments and Contexts

This test was administered to all the 75 informants and their renditions of the targeted segments were transcribed and categorized as a unit. The next section, therefore, focuses on the realization of these phonological segments, within the real context of their uses. The following table presents the 75 teachers' renditions of the above segments. 


\begin{tabular}{|c|c|c|c|c|c|c|}
\hline \multirow{2}{*}{$\begin{array}{l}\text { Words /words } \\
/ \text { dz/Cabbage }\end{array}$} & \multirow{2}{*}{$\begin{array}{l}\text { SBE } \\
/ d_{3} /: / \text { Kæbidz/ }\end{array}$} & \multirow{2}{*}{$\begin{array}{l}\text { CamE } \\
/ \mathrm{g} / / \text { Kabe } /\end{array}$} & \multicolumn{2}{|c|}{ Infmnts' Renditions } & \multirow{2}{*}{$\begin{array}{l}\text { Freq. } \\
9\end{array}$} & \multirow{2}{*}{$\begin{array}{l}\% \\
12 \%\end{array}$} \\
\hline & & & $/ \mathrm{d}_{3} /$ & Kæbidz & & \\
\hline & & & $/ g /$ & /KabeJ/ & 55 & $73.34 \%$ \\
\hline & & & $/ \mathrm{t} \mathrm{f} /$ & /Kabet $/ /$ & 11 & $14.66 \%$ \\
\hline & & & & & 75 & $100 \%$ \\
\hline \multirow[t]{3}{*}{ /ð/Southern } & /ð/: /sı爻ən/ & /d/: /sauden/ & /ð/ & 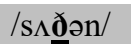 & 7 & $9.33 \%$ \\
\hline & & & $/ \mathrm{d} /$ & /sauden/ & 68 & $90.67 \%$ \\
\hline & & & & & 75 & $100 \%$ \\
\hline \multirow[t]{3}{*}{$/ \theta / \underline{\text { thought }}$} & $/ \theta /: / \theta \mathrm{pt} /$ & $/ \mathrm{t} /:$ /tot/ & $/ \theta /$ & $/ \theta \mathrm{pt} /$ & 13 & $17.33 \%$ \\
\hline & & & $/ \mathrm{t} /$ & /tot/ & 62 & $82.67 \%$ \\
\hline & & & & & 75 & $100 \%$ \\
\hline \multirow[t]{6}{*}{$/ \mathrm{t} J / \underline{\text { church }}$} & $/ \mathrm{t} f / / \mathbf{t}[\mathbf{3} \underline{\mathbf{t}} \mathrm{f} /$ & $/ \mathrm{t} \mathrm{J} / / \mathbf{t}[\mathbf{o t}[/$ & $/ \mathrm{t} \mathrm{f} /$ & $/ \mathrm{t} \int 3 \mathrm{t} \int /$ & 7 & $9.33 \%$ \\
\hline & & & $/ \mathrm{t} \mathrm{f} /$ & $/ \mathrm{t} \int \mathrm{st} \int /$ & 60 & $80 \%$ \\
\hline & & & $|\mathrm{s}|$ & $\mid \sqrt{3} \int \mathrm{j} /$ & 4 & $5.34 \%$ \\
\hline & & & $/ \mathrm{d} 3 /$ & dzot $\int /$ & 3 & $4 \%$ \\
\hline & & & /dz/WFP & dzodz & 1 & $1.33 \%$ \\
\hline & & & & & 75 & $100 \%$ \\
\hline \multirow[t]{4}{*}{ /a/ about } & /a/ /ạbaut/ & /a/ /abaut/ & /a/ & /ọbaut/ & 12 & $16 \%$ \\
\hline & & & /a/ & /abaut/ & 43 & $57.33 \%$ \\
\hline & & & /e/ & /ebaut/ & 20 & $26.67 \%$ \\
\hline & & & & & 75 & $100 \%$ \\
\hline \multirow[t]{3}{*}{$/ 3 /$ church } & & $/ \mathrm{o} / \mathrm{t} \mathrm{t} \mathrm{t} \mathrm{d} /$ & $\mid 3 /$ & $/ \mathrm{t} \int \underline{\underline{3}} \mathrm{t} \int /$ & 4 & $5.34 \%$ \\
\hline & & & $/ 0 /$ & $/ \mathrm{t} \int \mathrm{t} \mathrm{t} /$ & 71 & $94.66 \%$ \\
\hline & & & & & 75 & $100 \%$ \\
\hline \multirow[t]{4}{*}{ /ou/goat } & /əu//gəठt/ & /o/ /got/ & /ou/ & /gəot/ & 6 & $8 \%$ \\
\hline & & & /o/ & /got/ & 65 & $86.66 \%$ \\
\hline & & & $/ \mathrm{u} /$ & /gut/ & 4 & $5.34 \%$ \\
\hline & & & & & 75 & $100 \%$ \\
\hline \multirow[t]{4}{*}{ /əठə/ slower } & 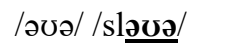 & /owa//slowa/ & /ə0ə/ & /sləü/ & 9 & $12 \%$ \\
\hline & & & lowa/ & /slowa/ & 62 & $82.66 \%$ \\
\hline & & & /owe/ & /slowe/ & 4 & $5.34 \%$ \\
\hline & & & & & 75 & $100 \%$ \\
\hline \multirow[t]{4}{*}{ /aøə/power } & /pavə/ & /awa/ & /aøə/ & /pavə/ & 4 & $5.34 \%$ \\
\hline & & & /awa/ & /pawa/ & 11 & $14.66 \%$ \\
\hline & & & /a:/ & /pa:/ & 60 & $80 \%$ \\
\hline & & & & & 75 & $100 \%$ \\
\hline
\end{tabular}

\section{Table 4: Informants' Renditions of targeted Phonological Segments}

As illustrated on table 4 , the informants realized the tested linguistic variables in different ways. Though some of their renditions were typical of SBE pronunciation, they were not consistent. There was, for example, an instance where an informant, in reading out the following sentence:

1) James is inside, searching for the goats.

rendered the diphthong/ow/ in the word "goat" correctly but stressed the adverb, "in'side", which ends the first clause of the construction, word initially as though it were an adjective. Such inconsistencies were in fact quite evident in the speeches of all those who made conscious efforts to approximate SBE English features. The implication here is that, it is quite difficult for an Outer Cycle speaker to effectively fit within the phonological standards of the Inner Cycle. The more Outer Cycle speakers try to approximate SBE features, they unconsciously use hypercorrected forms which are neither features of the variety they master best nor of the target variety. Consider the rendition of the triphthong /avə/ in the word "power", for example. We notice that $80 \%$ of the informants realized it as /pa:/ which is a typical example of the hypercorrected approximation of the triphthong. Cameroonian speakers of English are most likely to say /pawa/ (Simo-Bobda 1994) and not /pa:/. There are, indeed, several other renditions on the table above, including "church" which some of them rendered as $/ \int_{3} \int /$ and "cabbage" which they realized as $/$ Kabet $\mathrm{f} /$, instead of $/ \mathrm{t} \int_{\underline{3}} \mathrm{t} f /$ and $/ \mathrm{KabId} 3 /$ respectively.

From the results, we noticed that the focus was more on CamE, SBE some new features which are neither observable in mainstream CamE nor SBE. It was then necessary to single out these categories for proper segmentation and better appreciation of what characterizes the ESL teachers' speech the most. The following table, therefore, shows the distribution of the various renditions of specific linguistic variables in terms SBE, CamE, and new specific features in the informants' speeches. 


\begin{tabular}{cccc}
\hline Varieties & CamE Freq. (\%) & SBE Freq. (\%) & New Features Freq. (\%) \\
\hline$/ \mathbf{d} /$ & $55(73.34 \%)$ & $9(12 \%)$ & $11(14.66 \%)$ \\
$/ \mathbf{d} /$ & $68(90.67 \%$ & $7(9.33 \%)$ & $00(00 \%)$ \\
$/ \mathbf{\theta} /$ & $62(82.67 \%)$ & $13(17.33 \%)$ & $00(00 \%)$ \\
$/ \mathbf{t} /$ & $60(80 \%$ & $7(9.33 \%)$ & $8(10.67 \%)$ \\
$/ \mathbf{\partial} /$ & $43(57.33 \%)$ & $12(16 \%)$ & $20(26.67 \%)$ \\
$/ \mathbf{3} /$ & $71(94.66 \%)$ & $4(5.34 \%)$ & $00(00 \%)$ \\
$/$ ou/ & $65(86.66 \%)$ & $6(8 \%)$ & $4(5.34 \%)$ \\
$/$ ovə/ & $62(82.66 \%)$ & $9(12 \%)$ & $4(5.34 \%)$ \\
$/$ ava/ & $11(14.66 \%)$ & $4(5.34 \%)$ & $60(80 \%)$ \\
& & $\mathbf{7 1 ( 1 0 . 5 1 \% )}$ & $\mathbf{1 0 7}(\mathbf{1 5 . 8 5 \% )})$ \\
Total & $\mathbf{4 9 7}(\mathbf{7 3 . 6 2 \% )}$ & $\mathbf{6 7 5}$ & \\
\hline
\end{tabular}

Table 6: Distribution of ESL Teachers' Approximation of Specific Phonological Variables

This statistics is perhaps clearer on Figure 1 below.

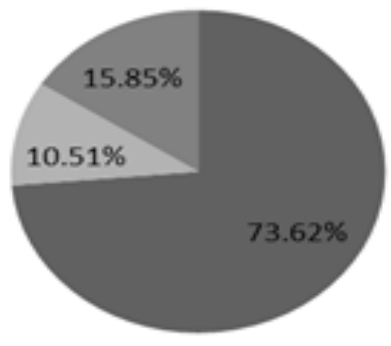

- CamE

= SBE

new Features

Figure 1: Distribution of ESL Teachers' Approximation of Specific Phonological Variables

These results show that ESL teachers in Cameroon are most likely to use CamE in formal and informal contexts than any other varieties in the country. It also suggests that ESL teachers, in an effort to approximate SBE features, are most likely to be victims of hypercorrection. Consequently, while ESL teachers in Cameroon may think highly of their English, by identifying more with SBE, they are eloquent speakers of CamE. This is so because there is a marked disparity between the informants' linguistic perception and their phonological renditions. Consider, for example, their perceptions and renditions of CamE on figure 2.

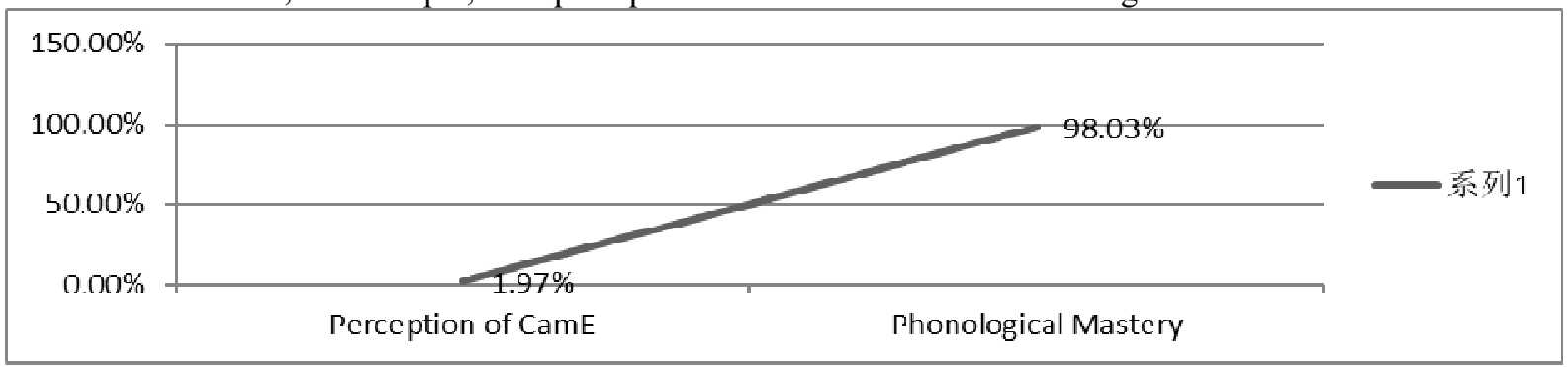

Figure 2: Perception of CamE and Phonological Mastery

Figure 2 clearly presents the variation in the perception and mastery of CamE features. While the informants' impression about their usage of CamE features is relatively low (1.97\%), CamE features are quite recurrent $(98.03 \%)$ in their speeches. This was a direct contrast to what obtained with the perceptions and renditions of SBE features.

\subsection{Discussion and Conclusion}

The findings reveal very serious pedagogic and sociolinguistic implications in the teaching and using of English in Cameroon. Pedagogically, it suggests that while the recommended variety of English Language teaching in the country is SBE, ESL teachers unconsciously use CamE as a medium of instruction. Consequently, the extent to which SBE is attained in our classrooms is highly questionable, even when lesson objectives are attained. The reason is basically because the mastery of a language is in the performance and hardly in the competence. Continuous emphasis on SBE features in our classrooms, therefore, only ridicules the entire English Language Teaching and Learning industry in the country. The findings, by implication, cut across the basic and secondary and tertiary levels of education in Cameroon. ESL student teachers, in the teacher training colleges, are trained by renowned professors who are observably eloquent speakers of, what could be referred to as, educated variety of CamE. After their training, the student teachers are deployed to various secondary schools and Grade One 
colleges to teach and train Grade One teachers who in turn would be employed to teach in the primary school and so the cycle continues.

Importing native teachers to give Cameroonians a near-native competence, is not even an option, since besides its huge financial demands and the dense multi-linguistic nature of Cameroon, it has recently been argued that educated Anglophone speakers of English are gradually getting comfortable with the use of CamE as the model of English Language teaching and learning in the country (Atechi and Angwah 2016). Effective language teaching requires that the target variety of a language is used to teach the language, without which the variety, used in teaching, is what the learners are likely to master best. Since Cameroon English is what the teachers use, it is only right, that it gains its rightful place in the Cameroonian teaching and learning industry. Besides the effective mastery of CamE (as perhaps the target variety in the country), learners are also likely to master the Cameroonian culture which is significantly expressed in this variety. Consequently, through the use of CamE on the global stage, Cameroon's culture gains a space on the international platform as well as commune with other linguistic cultures.

\section{References}

Anchimbe, E. (2006). Cameroon English: Authenticity, Ecology and Evolution. FrankfurtMain: Peter Lang.

Atechi, S. (2010)."The Plurality of English in Cameroon and the International Intelligibility Question."Syllabus Review, 1(2) 199- 218.

Atechi, S. (2006). The Intelligibility of Native and Non-Native English Speech.Gottingen: Cuvillier Verlag.

Atechi, S. and Angwah, J. (2016). "The Attitudes of Anglophone and Francophone Cameroonians towards Cameroon English as a Model of English Language Teaching and Learning in Cameroon." Journal of Education and Practice, 7(13) 109-115.

Bamgbose, A. (1998)."TornBetween the Norms! Innovations."World Englishes, 17(1) 1- 14

Kachru, B. B. (1985). "Standards, Codification and Sociolinguistic Realism: The English Language in the Outer Circle," In Quirk and Widdowson (eds).

Labov, W. (1966).The Social Stratification of English in New York City. Washington, DC: Center for Applied Linguistics.

Masanga, D. (1983).The Spoken English of Educated Moghamo People: A phonological study. Unpublished Doctorate de 3e Cycle thesis. University of Yaounde I.

Mbangwana, P. (1987). "Some Characteristics of Sound Patterns of Cameroon Standard English." Multilingual, 6(4) 411-424.

Neufeld, E. (1988). "On relation between defaults and probabilities". In Proceedings of the Third Annual University of Buffalo Graduate Conference on Computer Science, pages 39-45.

Ngefac, A. (2010) "Cameroon English accent: Issues of standardization, Attitudes and Pedagogic concerns." Journal of Languages and Culture.Vol. 1(1), 1-7.

Ngefac, A. (2008). Social Differentiation in Cameroon English: Evidence from Sociolinguistic Fieldwork. New York: Peter Lang.

Schmied, J. (2006).“East African Englishes”. The Handbook of World Englishes. Ed. Braj B. Kachru, Yamuna Kachru, Cecil L. Nelson, 188-202

Sey, K.(1973).Ghanaian English: An Exploratory Survey. London: Macmillan.

SimoBobda, A. (1994). Aspects of Cameroon English Phonology. Peter Lang, Inc.; European Academic Publishers, Bern.

Strange, W. (1982). "Effects of Phonological and Phonetic Factors on Cross Language Perception of Approximants."Haskins lAboratoriu Status \&port on Speech Resarch, 1(2) 89-108. 